$\mathbb{T}$ periodica polytechnica

Civil Engineering

$56 / 1(2012) 79+85$

doi: 10.3311/pp.ci.2012-1.09

web: http://www.pp.bme.hu/ci

(c) Periodica Polytechnica 2012

RESEARCH ARTICLE

\section{A novel approach for road runoff sampling}

\author{
Péter Budai / Adrienne Clement
}

Received 2010-11-10, revised 2011-07-04, accepted 2011-11-23

\begin{abstract}
Conventional methods of road runoff sampling come with various difficulties. Hence, a novel experimental method was tested in and around Budapest, using a passenger car to collect wheel splash samples. Total concentrations of selected heavy metals were compared to the results of an earlier conventional runoff sampling program for verification. Despite the inhomogeneous set of splash samples, the ratio of measured heavy metals was found to be fairly stable throughout the entire data set. Ratios in the new splash samples and the formerly collected gully drain runoff samples were also found to be identical, showing that sample composition is not distorted by the new method. Urban sites generally exhibited higher concentrations than motorway sites, especially for $\mathrm{Cu}$ and $\mathrm{Pb}$, the suspected cause of which is the difference in traffic dynamics. Traffic volume dependence is indirectly indicated by the clearly observable differences between weekday and weekend samples collected from urban sites.
\end{abstract}

\section{Keywords}

diffuse pollution · highway runoff · urban runoff · sampling · storm water

\section{Acknowledgement}

This work is connected to the scientific program of the "Development of quality-oriented and harmonized $R+D+I$ strategy and functional model at BME" project. This project is supported by the New Széchenyi Plan (Project ID: TÁMOP-4.2.1/B09/1/KMR-2010-0002).

\section{Péter Budai}

Department of Sanitary and Environmental Engineering, Budapest University of Technology and Economics, H-1111 Budapest, Múegyetem rkp. 3, Hungary e-mail: pbudai@vkkt.bme.hu

\section{Adrienne Clement}

Department of Sanitary and Environmental Engineering, Budapest University of Technology and Economics, H-1111 Budapest, Múegyetem rkp. 3, Hungary e-mail: clement@vkkt.bme.hu

\section{Introduction and objectives}

Contamination of road runoff is an intricate diffuse pollution problem, characterized by the emission, buildup and wash-off of a wide range of pollutants, mainly occurring as, or attached to, particles [7]. In dry weather, particles are emitted by various friction processes (e.g. brake abrasion, tire and road wear) and combustion (engine exhaust). Depending on their settling velocity, these particles either accumulate on the nearby surfaces (coarse fraction) or remain suspended in the air for prolonged periods and are easily transported away from their point of emission by natural or traffic induced wind (fine fraction). Nevertheless, part of the fine fraction remains attached to vehicle parts (brake dust on wheel rims). In wet weather, three additional processes join the ongoing emissions, making a substantial contribution to the suspended solids load of surface runoff by mobilizing particulate and particulate-bound matter:

- Part of the previously accumulated contaminant mass gets entrained and washed off from impervious surfaces by the impact of raindrops and the flow of surface runoff.

- The efficiency of this wash-off process is strongly enhanced on road surfaces by the intensive suction and pressure exerted by rolling vehicle wheels that splash the surface runoff (also washing off contamination from the wheels and chassis).

- A considerable part of the otherwise airborne mass gets deposited by precipitation.

Due to the complex nature of the contaminating processes, sampling of road contamination is difficult. A number of different solutions exist which are often not representative of each other. Sampling methods can be roughly classified into two groups, differing in the presence of real precipitation. Dry weather methods include vacuuming/sweeping and tunnel studies (providing information on coarse and fine particle accumulation and emission during dry periods) as well as artificial flushing (providing information on the fraction of contamination which is easily detached and entrained by the impact of raindrops and the surface flow of runoff). Such measurements are often difficult to organize and execute (permission, traffic 
restriction, weather surprises, etc.). The obtained results are important for process identification, yet they essentially fall short of reflecting the effects of additional contamination from wet weather processes.

In wet weather, the actual runoff is usually sampled at fix locations by either active or passive devices at some point of the drainage pathway (anywhere between the edge of the road surface and detention ponds). In the case of particulate and particulate-bound contaminants, which tend to settle out or get adsorbed during runoff routing, the measured concentrations depend heavily on the point of sampling (roadside curb, gully, swale, pond, etc.). This is confirmed e.g. by Desta et al [11], who reported significantly differing pollutant concentrations in road runoff from Irish highways with different drainage systems; and Crabtree et al. [8], who studied the pollutant reduction potential of various drainage systems. It is apparent, that wet weather samples taken at different points of the drainage system represent net contaminant wash-off which is usually valid only for the site-specific drainage and sampler placement. As a consequence, the sensible comparison of reported literature values, which usually span over a wide range, is de facto hampered.

A summary of some relevant literature data for total $\mathrm{Zn}$ and $\mathrm{Cu}$ in road runoff is presented in Fig. 1, 2 and Tab. 1. Intersite differences are best reflected by mean and median values, which vary about an order of magnitude. Comparison of statistics is somewhat hindered though, as some studies cover dozens of sites, while others focus on a few or just one. The choice of sampling period complicates the issue further.

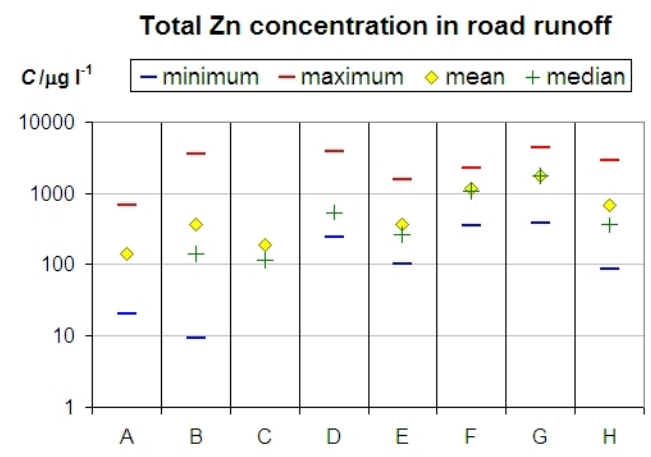

Fig. 1. Statistical values for total $\mathrm{Zn}$ "event mean concentration" (EMC) in road runoff given by various studies (see Tab. 1 ).

Additional data from the USA is cited by Kayhanian et al. [16], which provide median EMC values between $15-43 \mu \mathrm{g}^{-1}$ for $\mathrm{Cu}$, and 202-222 $\mu \mathrm{g} \mathrm{l}^{-1}$ for $\mathrm{Zn}$ (AADT range: 5,000-200,000 vehicle day ${ }^{-1}$ ). The study of a low-traffic (AADT: 6,000 vehicle day $^{-1}$ ) nonurban road in Portugal [1] yielded only 5 and 3 EMC data for $\mathrm{Cu}$ and $\mathrm{Zn}$, respectively, the average values of which are 24.1 and $308 \mu \mathrm{g} \mathrm{l}^{-1}$. Desta et al. [11] reported mean total $\mathrm{Cu} / \mathrm{Zn}$ concentrations for a curb-and-gully site as $0.12 / 0.66 \mathrm{mg} \mathrm{l}^{-1}$, and for a filter drain site as $0.03 / 0.12 \mathrm{mg} \mathrm{l}^{-1}$ (both sites had similar traffic volumes and climatic properties, and were sampled in the same period).
Total $\mathrm{Cu}$ concentration in road runoff

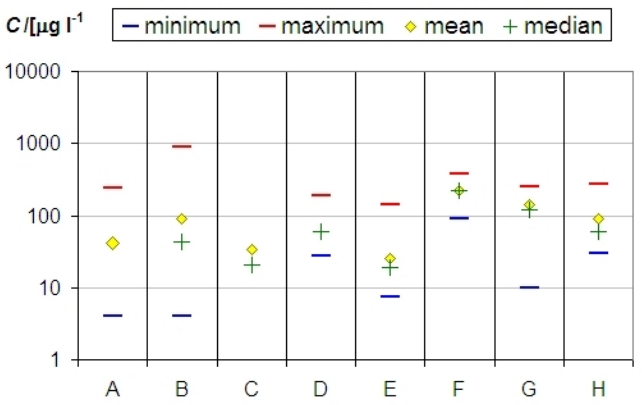

Fig. 2. Statistical values for total $\mathrm{Cu}$ "event mean concentration" (EMC) in road runoff given by various studies (see Tab. 1 .

In order to gain comparable information from different sites, the retention effects of the drainage system should be eliminated, so that samples represent the gross contaminant wash-off (combined mobilization of pollutants by rainfall and vehicle-forced detachment). The straightforward idea is that sampling should be executed as close to the emission sources as possible. A suitable collection method seems to be the utilization of vehicles equipped with appropriate samplers to collect splashed water directly from the road surface while driving in the traffic. In addition, this new kind of wet weather sampling method offers much greater mobility compared to the usual methods (one vehicle can collect samples from multiple locations during one rainfall event). It also seems to be capable of investigating the supposed differences between the mobilization potential of various vehicle types (passenger cars vs. heavy duty vehicles) in detail. The goal of this paper is to present the results of a test campaign, and to evaluate the reliability and applicability of wheel splash sampling.

\section{Methodology}

Experiments with wheel splash sampling were conducted with a passenger car. A small buffer container was mounted securely behind the rear left wheel to catch and temporarily hold the splashed water. A flexible plastic pipe was submerged in this container, through which the captured water was continuously lifted by a Thomas 415 CDC type vacuum pump into larger glass bottles inside the car. The sketch of the sampler layout is depicted in Fig. 3

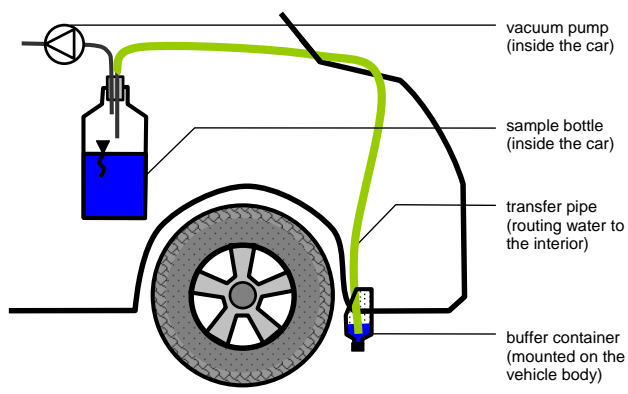

Fig. 3. Layout of the wheel splash sampler. Drawing is not to scale.

To obtain a fairly inhomogeneous set of samples for thorough 
Tab. 1. Background information for Figs.112 AADT stands for "annual average daily traffic". NA stands for "not available".

\begin{tabular}{|c|c|c|c|c|c|c|c|}
\hline & study & AADT vehicle day $^{-1}$ & sample size & sampled sites & location (vicinity) & time & sampling layout \\
\hline $\mathbf{A}$ & Crabtree et al. 8 & $23,647-83,579$ & 60 & 6 nonurban & England, UK & $1997-2003$ & various \\
\hline $\bar{B}$ & Crabtree et al. 9$]$ & $<15,000-120,000<$ & 280 & 24 nonurban & England, UK & $2004-2008$ & NA \\
\hline$\overline{\mathbf{C}}$ & Kayhanian et al. 16 & $2,000-328,000$ & 635 & 34 urban \& non-urban & California, USA & $2000-2003$ & roadside conduits \\
\hline D & Gromaire-Mertz et al. 13. & NA & 26 & 6 urban street & Paris, France & 07/1996-05/1997 & streetside gully hole inlets \\
\hline $\bar{E}$ & Legret and Pagotto 18 & 12,000 & 49 & 1 nonurban motorway & France (Nantes) & 05/1995-02/1996 & bridge drain \\
\hline$\overline{\mathbf{F}}$ & Budai and Buzás 2 & 40,620 & 16 & 1 nonurban expressway & Hungary (Budapest) & 2006 summer & roadside gully drain \\
\hline$\overline{\mathbf{G}}$ & Gan et al. 12 & 22,170 & 11 & 1 urban motorway & China (Guangzhou) & 09/2005-07/2006 & streetside gully hole inlets \\
\hline $\mathbf{H}$ & Gan et al. 12 & 31,000 & 7 & 1 nonurban motorway & China (Guangzhou) & 04/2006-06/2006 & bridge drain \\
\hline
\end{tabular}

testing of the new method, a range of sampling sites were selected: 8 urban roads in Budapest and 10 motorway sections (6 around Budapest and 4 lying outside the country, for a regional outlook). A total of 32 and 26 samples were collected from these urban and motorway sites, respectively (Tab. 2). Travel logs were recorded by GPS, with start and finish location and time for each individual sample. The duration of sample collection and the travelled length per individual samples (a volume of 2 1) varied between urban and motorway sites (4-6 km and 8-12 km, respectively), depending on average traffic speed.

An earlier study of ours indicated that concurrent traffic volume has a great impact on the concentration of a range of pollutants in highway runoff [6], so attention was paid to select sites characterized by different traffic volumes. As weekdays and weekends generally differ in terms of traffic volume (especially in the case of urban roads), a substantial number of samples were taken in both periods. It was known in advance that there would be no concurrent traffic counts available for the urban sites, so an arbitrary classification was applied (consisting of 5 classes) to roughly describe the general traffic situation during sampling. As anticipated, traffic conditions varied greatly from site to site and event to event.

The sampled precipitation events included light and heavy rains as well as snowfall. In the absence of sufficiently detailed precipitation data for all sites, rainfall intensity was also classified by arbitrary judgement into 3 classes on the site. A total of 58 samples were collected from 10 events between September 2009 and April 2010.

The collected samples were stored in a refrigerator at $4{ }^{\circ} \mathrm{C}$ until analysis. TSS, COD, $\mathrm{pH}$, specific conductivity and total concentrations of 6 metals $(\mathrm{Zn}, \mathrm{Cu}, \mathrm{Pb}, \mathrm{Ni}, \mathrm{Cr}$, and $\mathrm{Cd})$ were determined from the samples. TSS was measured by filtration through a $0.45 \mu \mathrm{m}$ membrane, COD was determined using the dichromate method. For the analysis of metals, samples were first homogenized using ultrasonic bath. $40 \mathrm{ml}$ of homogenized sample was placed in a $100 \mathrm{ml}$ Teflon bomb, then $2 \mathrm{ml}$ of Suprapur $\mathrm{HNO}_{3}$ and $6 \mathrm{ml}$ of Suprapur $\mathrm{HCl}$ were added, and the sample was digested in an Anton Paar Multiwave 3000 digester according to the EPA 3015 method. The extract was filtered through a $0.45 \mu \mathrm{m}$ membrane, and measured by flame atomic absorption spectroscopy (FAAS) using a Perkin-Elmer 3030 spectrophotometer (for $\mathrm{Cu}, \mathrm{Cr}, \mathrm{Ni}, \mathrm{Pb}$, and $\mathrm{Zn}$ ), or graphite furnace atomic absorption spectrometry (GFAAS) using a Perkin-
Elmer Analyst 700 (for Cd). As this was a pilot study, samples were not analyzed for dissolved metal concentrations. The partitioning of metal contaminants between particulate and dissolved forms in road runoff is discussed in detail by a handful of previous studies, e.g.: [13, 14, 16, 18].

To demonstrate the viability of wheel splash sampling, measured total metal concentrations were compared to values acquired by our earlier runoff sampling program at motorway site \#2. Samples were collected there for a 1.5 -year period with a passive sampler device, which was placed in the top section of a concrete gully drain that channels runoff from the roadside curb down a steep slope into a collecting conduit (further details in [2]). At this point of the drainage system retention is assumed to be mild, therefore samples collected here were regarded as being fairly representative of the raw form of road runoff, and thus, suitable for direct comparison with the wheel splash method. Metals were chosen as the basis of comparison because they are strongly related to traffic emissions [10].

\section{Results and discussion}

\subsection{Characterization of sampled water quality}

Mean, median, maximum and minimum values of measured water quality parameters from the wheel splash samples are presented in Tab. 3. As sample collection always began later than the initial portion of runoff left the road surface, elevated pollutant concentrations that characterize this first part of the runoff are very unlikely to be represented in the data set.

Fig. 4 presents box plots of total $\mathrm{Zn}, \mathrm{Cu}, \mathrm{Ni}, \mathrm{Cr}$ and $\mathrm{Pb}$ concentrations for three data sets: urban and motorway splash from the new campaign, and motorway gully drain samples from our earlier study ( $\mathrm{Cd}$ is not presented because of insufficient data from the latter). As expected, metal concentrations in the motorway splash samples are in the same order of magnitude, but usually a little higher than those of the motorway gully drain samples. Note that the gully drain sampling campaign provided a set of concentration time-series (including first flush periods) for a number of individual precipitation events at one particular site, while wheel splash sampling provided a set of grab samples representing the longitudinal average concentration from a group of distinct road sections for a number of individual precipitation events. As a consequence, the distribution of the gully drain samples is somewhat skewed towards higher concentrations if compared to the splash samples. 
Tab. 2. Sample collection sites and number of weekday/weekend samples collected. AADT stands for "annual average daily traffic". Traffic data for urban sites are estimates based on occasional counts [17], while those for motor- ways and expressways are data from continuous automatic counts (the number of heavy duty vehicles is given in brackets). Traffic data for sites \#1-6 are from 2008 [19], for sites \#7-9 from 2008 [4], for site \#10 from 2005 [5].

\begin{tabular}{|c|c|c|c|c|}
\hline Site ID & Site name & weekday & weekend & AADT, vehicle day ${ }^{-1}$ \\
\hline \multicolumn{5}{|c|}{ Urban roads within Budapest } \\
\hline$\# 1$ & Mester st. & 2 & 2 & 9,600 \\
\hline \#2 & Pázmány Péter quay & 3 & 1 & 9,000 \\
\hline \#3 & Petőfi bridge & 4 & 2 & 67,000 \\
\hline$\# 4$ & Soroksári st. & 3 & 2 & 46,000 \\
\hline \#5 & Ferenc blvd. - Teréz blvd. & 1 & 2 & 41,000 \\
\hline$\# 6$ & Üllői st. & 3 & 2 & 44,000 \\
\hline$\# 7$ & Irinyi József st. - Nagyszőlős st. & 3 & 1 & 38,000 \\
\hline \#8 & Bartók Béla st. & 1 & 0 & 43,000 \\
\hline \multicolumn{5}{|c|}{ Motorways and expressways } \\
\hline$\# 1$ & M1/M7 common section (6-12 km) & 3 & 2 & $130,353[5,483]$ \\
\hline \#2 & M0 Southwest (4-14 km) & 4 & 2 & $51,603[13,327]$ \\
\hline \#3 & M0 South (16-28 km) & 2 & 1 & $72,781[17,819]$ \\
\hline$\# 4$ & M0 Southeast (31-41 km) & 1 & 1 & $18,717[4,137]$ \\
\hline$\# 5$ & M7 (16-28 km) & 3 & 1 & $47,293[6,810]$ \\
\hline$\# 6$ & M5 (17-22 km) & 1 & 1 & $65,626[14,635]$ \\
\hline$\# 7$ & A8 (Bernau am Chiemsee) & 1 & 0 & $52,794[6,899]$ \\
\hline \#8 & A8 (Augsburg-Ost) & 0 & 1 & $64,952[9,862]$ \\
\hline$\# 9$ & A8 (Dachau) & 0 & 1 & $84,835[10,291]$ \\
\hline$\# 10$ & A21 (15-26 km) & 0 & 1 & $30,261[7,224]$ \\
\hline
\end{tabular}

Tab. 3. Measured pollutant concentrations and other water quality parameters in 58 wheel splash samples collected at 18 urban and motorway sites from

\begin{tabular}{lcccccccccc}
\hline & TSS & COD & pH & $\lambda$ & Total Zn & Total Cu & Total Ni & Total Cr & Total Pb & Total Cd \\
\hline & $\mathrm{mg} \mathrm{I}^{-1}$ & $\mathrm{mg} \mathrm{I}^{-1}$ & & $\mathrm{mS} \mathrm{cm}^{-1}$ & $\mu \mathrm{g} \mathrm{I}^{-1}$ & $\mu \mathrm{g} \mathrm{I}^{-1}$ & $\mu \mathrm{g} \mathrm{I}^{-1}$ & $\mu \mathrm{g} \mathrm{I}^{-1}$ & $\mu \mathrm{g} \mathrm{I}^{-1}$ & $\mu \mathrm{g} \mathrm{I}^{-1}$ \\
\hline mean & 3543 & 710 & 8.19 & 3.992 & 1934 & 590 & 103 & 96 & 181 & 1.22 \\
\hline median & 2219 & 484 & 8.13 & 0.384 & 1278 & 435 & 64 & 66 & 131 & 0.70 \\
\hline maximum & 32673 & 3430 & 9.14 & 40.200 & 11736 & 2508 & 835 & 540 & 1175 & 7.61 \\
\hline lower quartile & 932 & 273 & 7.79 & 0.198 & 863 & 281 & 35 & 26 & 66 & 0.11 \\
\hline upper quartile & 3493 & 855 & 8.51 & 1.764 & 2143 & 678 & 110 & 104 & 204 & 1.19 \\
\hline
\end{tabular}

Box plots of total $\mathrm{Zn}, \mathrm{Cu}, \mathrm{Ni}, \mathrm{Cr}$ and $\mathrm{Pb}$ concentrations

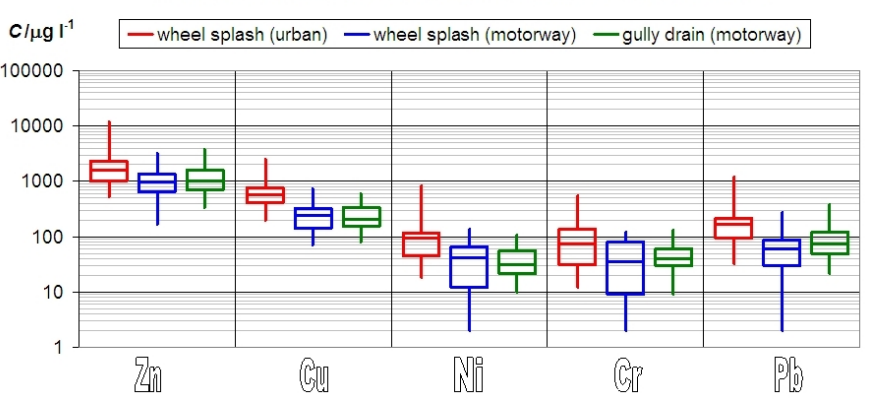

Fig. 4. Box plots of total $\mathrm{Zn}, \mathrm{Cu}, \mathrm{Ni}, \mathrm{Cr}$ and $\mathrm{Pb}$ concentrations for wheel splash and gully drain sample sets. Maximum, minimum, median, lower and upper quartile values are shown.

\subsection{Impacts of traffic and snow on runoff water quality}

Fig. 5 and 6 present total $\mathrm{Zn}, \mathrm{Cu}$ and $\mathrm{Pb}$ concentrations for two urban sites, five distinct events for each one. A clear difference can be seen between weekday and weekend samples: the former are consequently higher than the latter. The obser- vation is reassured by the rest of the urban sites as well. Since urban traffic volumes and flows show significant differences between weekdays and weekends (the former being characteristically higher), this pattern supports the overall importance of traffic parameters determining the quality of road runoff. Due to the lack of thorough traffic counts during the time of sampling, no quantitative relationship between traffic volume and contaminant concentrations can be established from this data set. Such relationships, with certain limitations, can be derived from our earlier gully drain runoff sampling program, however [6]. Further research needs to be done to gain more widely applicable results.

From Fig. 4 one can also see that splash samples from urban sites show generally higher concentrations than the ones from motorway sites. This is especially true in the case of $\mathrm{Cu}$ and $\mathrm{Pb}$, where the urban figures are, on average, $2.5( \pm 0.4)$ and $2.7( \pm 0.4)$ times higher, respectively. As $\mathrm{Cu}$ is predominantly originating from brake lining wear, and to a lesser degree, but 
$\mathrm{Pb}$ is also a component of brake lining [10, 15, 23], it is very likely that this reflects the differences in traffic dynamics: traffic lights and peak hour "stop-and-go" traffic in town both induce higher braking frequency and intensity, resulting in elevated emissions of brake-wear specific materials. The Ni and $\mathrm{Cr}$ concentrations of splash samples are more widely distributed than those of the gully drain samples, the reason of which is yet unknown. The least difference between the three subsets is for $\mathrm{Zn}$, where the average urban-to-motorway ratio was found to be $1.6( \pm 0.2)$. The three latter metals are known to be less sourcespecific than $\mathrm{Cu}$ and $\mathrm{Pb}$ (e.g. $\mathrm{Zn}$ originates from tire abrasion, brake wear and roof material as well).

Total $\mathrm{Zn}, \mathrm{Cu}$ and $\mathrm{Pb}$ concentrations $\mathrm{C} / \mathrm{mg} \mathrm{l}^{-1}$ in splash samples from urban site \#6

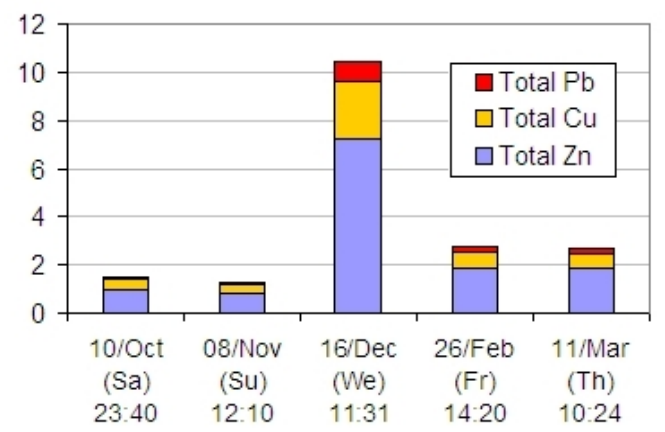

Fig. 5. Total concentrations of $\mathrm{Zn}, \mathrm{Cu}$ and $\mathrm{Pb}$ in splash samples at urban site \#6 for five distinct precipitation events.

Total $\mathrm{Zn}, \mathrm{Cu}$ and $\mathrm{Pb}$ concentrations $\mathrm{C} / \mathrm{mg} \mathrm{l}^{-1}$ in splash samples from urban site \#4

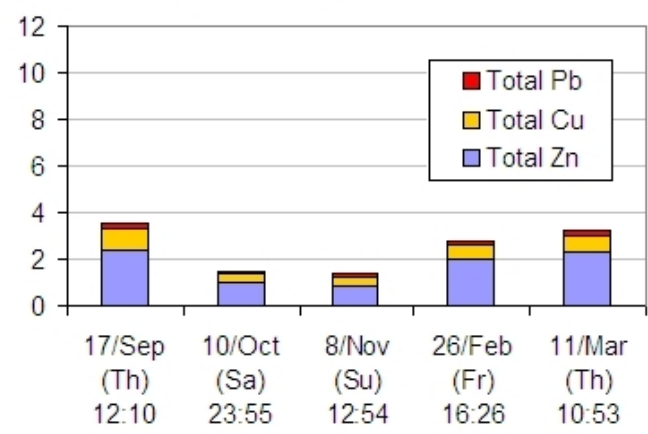

Fig. 6. Total concentrations of $\mathrm{Zn}, \mathrm{Cu}$ and $\mathrm{Pb}$ in splash samples at urban site \#4 for five distinct precipitation events.

The highest concentrations in the entire sample set were observed from a winter snowfall (and melt) event preceded by a prolonged cold period, during which most of the snow from the previous snowfall, ploughed out to the roadside, did not melt. Fig. 5 features one of these samples, showing extraordinarily high metal concentrations compared to the rest of the events. This confirms the results of other studies [14,18,21] which identify the reasons as the pollutant-trapping capability of the roadside snow matrix and the increased corrosion caused by de-icing agents. Apart from the snow bank acting as a repository for coarser metal particles, the additional adsorption of fine airborne particles to the snow crystals may also contribute to the overall accumulation. As a considerable fraction of abraded brake material is emitted as airborne particulate matter [3, 20], and further fine metal particles are emitted by tire wear and fuel combustion [22], this contamination pathway may not be negligible, either.

\subsection{Verification of the wheel splash sampling method}

The reliability, and thus, the further application of the wheel splash sampling method depends on how representative the collected samples are of the road surface runoff. Two questions arise: whether contaminants washed off from the sampler vehicle represent a substantial contribution to the sample or not, and whether they do distort the sample composition or not. These issues were investigated by comparing the new samples with those from our earlier gully drain runoff sampling program. If metal concentrations in the splash samples were to be found in a narrow range, being highly insensitive to site and event characteristics, or if their relative amounts were to be clearly different compared to those of the gully drain samples, the disturbance of "self-sampling" would pose serious difficulties in using the new method.

In contrary, Fig. 4 shows clearly that the total metal concentration ranges of splash samples were even wider than those of the gully drain samples. The high values found in snowmelt events (one of which is depicted on Fig. 5) also demonstrate that wheel splash samples describe the road runoff at the time and place of sampling, rather than actual wash-off from the vehicle which is used for sample collection. The relative ratios of total $\mathrm{Zn}, \mathrm{Cu}, \mathrm{Pb}, \mathrm{Ni}$ and $\mathrm{Cr}$ were found to be fairly steady throughout the whole range of splash samples (with a slight but consistent difference between urban and motorway subsets, resulting from the differences in $\mathrm{Cu}$ and $\mathrm{Pb}$ due to traffic dynamics), just like they were in the gully drain samples, too. Furthermore, comparing the ratios for the site where both sampling methods were applied, these ratios are identical (Fig. 7) and 8). This similarity supports the hypothesis that sample composition does not get distorted in splash samples, suggesting that on-the-run splash sample collection by vehicles is interchangeable with the gully drain sampling method.

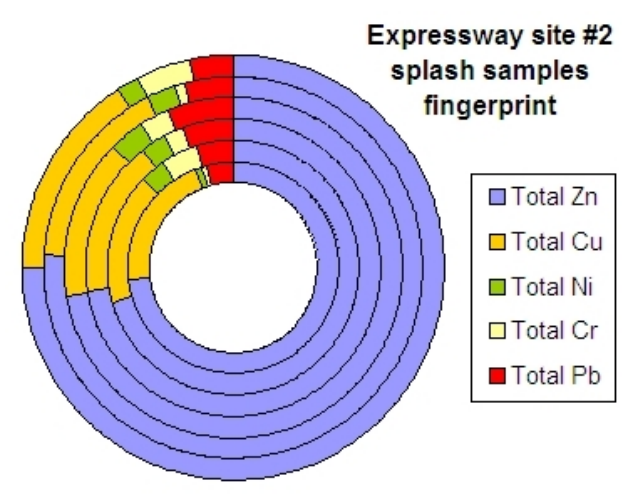

Fig. 7. Fingerprint showing the relative quantity of five metals from the wheel splash sampling campaign at motorway site \#2. Each ring denotes one distinct event. 


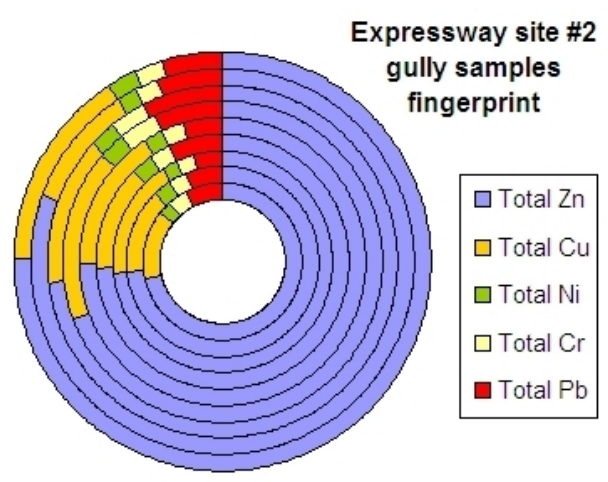

Fig. 8. Fingerprint showing the relative quantity of five metals from the gully drain sampling campaign at motorway site \#2. Each ring denotes one distinct event.

The supposed causes of the mild variation experienced between the distinct events (for both the splash and the gully drain samples) are the different traffic and precipitation parameters. In order to test this hypothesis, the relative ratios in the time-series of individual precipitation events from the gully drain samples were also assessed. It was assumed that due to less inhomogeneity in traffic and precipitation parameters during the course of one precipitation event, the ratios will show even less variation (compared to those between distinct events). The results show that, regardless of which part of the time series is looked at, the ratios are indeed steadier, in fact almost completely unchanged (Fig. 9 and 10 show an example). Despite this successful indirect proof, further targeted measurements and analysis of the metal ratios is needed to investigate the causes thoroughly.

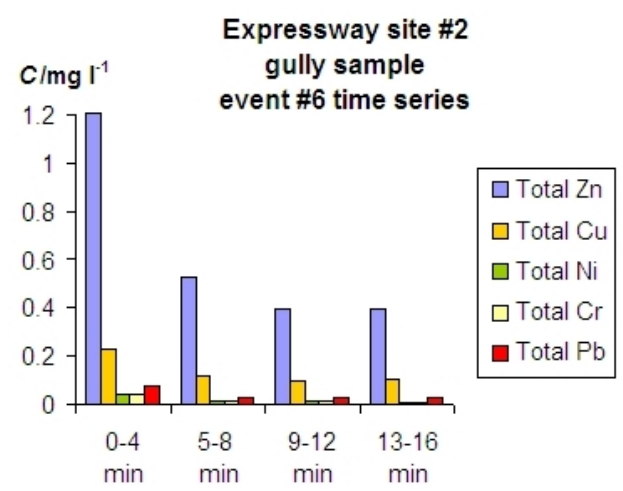

Fig. 9. Time-series showing the absolute quantity of five metals at motorway site \#2 during one precipitation event. The first flush effect is apparent for all studied metals.

\section{Conclusions}

A novel method of road runoff sampling was proposed and tested on urban roads and motorways in and around Budapest: a passenger car was equipped to collect wheel splash samples. Total concentrations of selected heavy metals were compared to the results of an earlier gully drain runoff sampling program conducted at an expressway which was also included in the new campaign. The major findings are the following:

- Despite the inhomogeneous set of splash samples, the ratio of
Expressway site \#2

gully sample, event \#6 time series

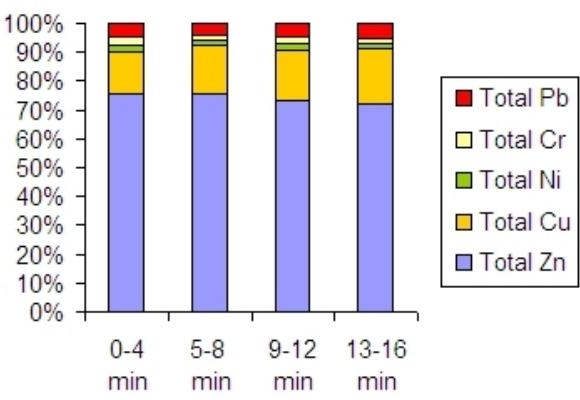

Fig. 10. Time-series showing the relative quantity of five metals at motorway site \#2 during one precipitation event. Ratios are stable throughout the whole event.

measured heavy metals was found to be fairly stable throughout the entire data set.

- Metal concentration ratios in splash samples and formerly collected gully drain runoff samples were also found to be identical. The little observed variation is suspected to be caused by differences in traffic and precipitation parameters from one event to another.

- Traffic volume dependence is indirectly indicated by the clearly observable differences between weekday and weekend samples collected at urban sites.

- Urban sites generally exhibit higher heavy metal concentrations than motorway sites, the suspected cause of which is the difference in traffic dynamics (frequency and intensity of braking). The difference is most pronounced for $\mathrm{Cu}$ and $\mathrm{Pb}$ and the least for $\mathrm{Zn}$, with respective urban-to-motorway concentration ratios of $2.5( \pm 0.4), 2.7( \pm 0.4)$ and $1.6( \pm 0.2)$.

The findings suggest that wheel splash method is a viable new alternative of road runoff sampling, especially useful in urban areas, where other conventional methods are usually hard to implement. In addition, wheel splash sampling offers much greater mobility, as one vehicle can collect samples from multiple locations during one rainfall event. The application of this sample collection method can be a powerful tool for a more detailed study focusing on the effect of traffic dynamics on runoff water quality in key urban sites.

\section{References}

1 Barbosa A E, Hvitved-Jacobsen T, Highway runoff and potential for removal of heavy metals in an infiltration pond in Portugal, Science of the Total Environment 235 (1999), no. 1-3, 151-159, DOI 10.1016/S00489697(99)00208-9.

2 Budai P, Buzás K, Highway runoff characterization in Hungary, 11th International Conference on Diffuse Pollution and the 1st Joint Meeting of the IWA Diffuse Pollution and Urban Drainage Specialist Groups (Belo Horizonte, Brasil, August 26, 2007). Published as CD, paper ID: PAP-0076.

3 Budai P, Clement A, Refinement of national-scale heavy metal load estimations in road runoff based on field measurements, Transportation Research Part D: Transport and Environment 16 (2011), no. 3, 244-250, DOI 10.1016/j.trd.2010.12.003. 
4 Bundesanstalt für Strassenwesen, Automatische Zählstellen auf Autobahnen und Bundesstrassen, 2008, available at http: //WwW.bast.de/cln_016/nn_42742/DE/Aufgaben/abteilung-v/ referat-v2/verkehrszaehlung/startseite.html online database.

5 Bundesministerium für Verkehr I. u. T., Strassenverkehrszählung 2005, 2007, available at http://www.bmvit.gv.at/verkehr/strasse/ autostrasse/statistik/downloads/ECEzaehlung2005.pdf

6 Buzás K, Budai P, Clement A, Contamination and treatment of highway runoff, Pollack Periodica 3 (2008), no. 3, 79-89, DOI 10.1556/Pollack.3.2008.3.7.

7 Buzás K, Somlyódy L, Impacts of Road Traffic on Water Quality, Periodica Polytechnica Civil Engineering 41 (1997), no. 2, 95-107.

8 Crabtree B, Moy F, Whitehead M, Roe A, Monitoring Pollutants in highway runoff, Water and Environment Journal 20 (2006), no. 4, 287-294, DOI 10.1111/j.1747-6593.2006.00033.x.

9 Crabtree B, Dempsey P, Johnson I, Whitehead M, The development of an ecological approach to manage the pollution risk from highway runoff, Water Science and Technology 59 (2009), no. 3, 549-555, DOI 10.2166/wst.2009.876.

10 Davis A P, Shokouhian M, Ni S, Loading estimates of $\mathrm{Pb}, \mathrm{Cu}, \mathrm{Cd}$, and $\mathrm{Zn}$ in urban runoff from specific sources, Chemosphere 44 (2001), no. 5, 9971009, DOI 10.1016/S0045-6535(00)00561-0.

11 Desta M B, Bruen M, Higgins N, Johnston P, Highway runoff quality in Ireland, Journal of Environmental Monitoring 9 (2007), no. 4, 366-371, DOI 10.1039/B702327H.

12 Gan H, Zhuo M, Li D, Zhou Y, Quality characterization and impact assessment of highway runoff in urban and rural area of Guangzhou, China, Environmental Monitoring and Assessment 140 (2008), no. 1-3, 147-159, DOI 10.1007/s10661-007-9856-2.

13 Gromaire-Mertz M C, Garnaud S, Gonzalez A, Chebbo G, Characterisation of Urban Runoff in Paris, Water Science and Technology 39 (1999), no. $2,1-8$.

14 Hallberg M, Renman G, Lundbom T, Seasonal Variations of Ten Metals in Highway Runoff and their Partition between Dissolved and Particulate Matter, Water, Air, and Soil Pollution 181 (2007), no. 1-4, 183-191, DOI 10.1007/s11270-006-9289-5.

15 Hjortenkrans D S T, Bergbäck B G, Häggerud A V, Metal Emissions from Brake Linings and Tires: Case Studies of Stockholm, Sweden 1995/1998 and 2005, Environmental Science and Technology 41 (2007), no. 15, 52245230, DOI 10.1021/es0701980.

16 Kayhanian M, Suverkropp C, Ruby A, Tsay K, Characterization and prediction of highway runoff constituent event mean concentration, Journal of Environmental Management 85 (2007), no. 2, 279-295, DOI 10.1016/j.jenvman.2006.09.024

17 Közlekedés Ltd., 2010. personal communication.

18 Legret M, Pagotto C, Evaluation of pollutant loadings in the runoff waters from a major rural highway, Science of the Total Environment 235 (1999), no. 1-3, 143-150, DOI 10.1016/S0048-9697(99)00207-7.

19 Magyar Közút Ltd., 2008 traffic count report of Hungarian highways, 2009. in Hungarian.

20 Sanders P G, Xu N, Dalka T M, Maricq M M, Airborne brake wear debris: size distributions composition and a comparison of dynamometer and vehicle tests, Environmental Science and Technology 37 (2003), no. 18, 4060-4069, DOI 10.1021/es034145s.

21 Sansalone J J, Buchberger S G, Characterization of Metals and Solids in Urban Highway Winter Snow and Spring Rainfall-Runoff, Transportation Research Record 1523 (1996), 147-159, DOI 10.3141/1523-18.

22 Sternbeck J, Skjödin A, Andréasson K, Metal emissions from road traffic and the influence of resuspension: results from two tunnel studies, Atmospheric Environment 36 (2002), no. 30, 4735-4744, DOI 10.1016/S13522310(02)00561-7.

23 Westerlund K-G, Metal Emissions from Stockholm Traffic - Wear of Brake Linings. Reports from SLB-analysis 3:2001, The Stockholm Environment and Health Protection Administration, 2001, http://miljobarometern. stockholm.se/content/docs/mg/westerlund_eng.pdf 